\title{
Correlation between the moisture and quantity of biomass as a basis of sustainability of ecosystems (the example of plain deserts of Turkmenistan)
}

\author{
V. Kostiukovsky \\ Albert Katz Department of Dryland Biotechnologies, \\ Jacob Blaustein Institutes for Desert Research, \\ Ben-Gurion University of the Negev, Israel
}

\begin{abstract}
The life activity and sustainability of ecosystems is determined by the correlation of all of their components, organic and non-organic. The correlation between moisture income and organic components in the authomorphic ecosystems of extra-arid plain deserts of Turkmenistan is examined. The area of $332790 \mathrm{sq} . \mathrm{km}$ of authomorphic ecosystems of Turkmenistan receives an average annual precipitation of 36740 billion metric tons. Nearly $8000-9000$ bill. m.t. of this quantity is involved in ecological processes and guarantees the life, sustainability and activity of 242,42 bill. m.t. of plant biomass (phytomass) and 4,82 bill. m.t. of animal biomass (zoomass). Consequently the proportion of these three components, water, phytomass and zoomass, is 1171:50:1. This proportion supports the existence of desert ecosystems in Turkmenistan under the significant seasonal, annual and multi-century climatic fluctuations, and may be used for planning, monitoring and rational use of natural resources
\end{abstract}

Keywords: Turkmenistan plain deserts, authomorphic ecosystems, correlation, moisture, biomass, phytomass, zoomass, sustainability.

\section{Introduction}

Sustainability of ecosystems is determined by correlation of all of their components, organic and non-organic. Any change in any particular aspect initiates a chain of changes in all of the other ones. An example is the seasonal 
and annual fluctuations of climate bringing periodical fluctuations in the dynamics of non-organic and organic elements of ecosystems, both in quantity and in quality. At the same time, sharp and sudden breaches of the existing equilibrium may lead to catastrophic consequences, possibly up to full destruction of all ecosystems. Consequently, the observation of this correlation between the various elements, components of entire ecosystems, is necessary for monitoring them and optimization of their life activity.

Connections and interactions between the elements composing these ecosystems are mostly evident under extreme conditions, where one or several of those factors that ensure the continued stability of ecosystems is limited. A noticeable example of deficiency of one of these factors - moisture - is the ecosystems of arid regions. Thus, the plain deserts of Turkmenistan may be used as a model for investigation of the dependence between the dynamics of organic elements of ecosystems on the moisture, particularly of the correlation between the quantity of precipitation, biomass of plants (phytomass) and biomass of animals (zoomass).

\subsection{Region of investigation}

The plains of Turkmenistan are situated in the central region of the Eurasian continent, at the northern part of a desert zone. More than $90 \%$ of this country consists of arid and extra-arid deserts. The average annual air temperatures here range from 12 to $18{ }^{\circ} \mathrm{C}$ (the winter minimum below $-25{ }^{\circ} \mathrm{C}$, the summer maximum over $45^{\circ} \mathrm{C}$ ). The annual precipitation income ranges from 70 to 200 $\mathrm{mm}$. There are a large number of sunny days (300-350 days per year), with direct solar radiation of 4000-4600 $\mathrm{mj} / \mathrm{sq}$. m. Frequent strong winds (average 3,2-4,2 $\mathrm{m} / \mathrm{sec}$, maximum more than $25 \mathrm{~m} / \mathrm{sec}$ ) provide high evaporation capacity of $1650-2300 \mathrm{~mm} /$ year [1]. Consequently, the coefficient of aridity is near 0,07 and the plains of Turkmenistan may be considered as extra-arid.

The strenuous water regime manifests in significant fluctuations in the quantity of phythomass and zoomass, which allows calculation of the correlations between these three elements of ecosystems.

\section{Sources of information and results}

The boundary of plain deserts of Turkmenistan have been defined as the shore of Caspian sea - at the West, and the national border - at the North and East (partly coinciding with the waterway of the Amudarya river). The mountainous part of Turkmenistan defines the desert to the south, the boundary of plain deserts being the horizontal line of $300 \mathrm{~m}$. above sea level, which mainly coincides with the isohiett (pluvial line) of $200 \mathrm{~mm}$. of precipitation per year. The area of authomorphic ecosystems of Turkmenistan plain deserts (excepting the anthropogenic territories and hydromorphic ecosystems of salt-marshes and river valleys and deltas) has been defined as 332790 sq. km. 
Circulation of moisture in ecosystems is connected closely with the geological composition of the soil. Consequently, the territory of plain deserts has been divided by this principle as sandy, stony-rubble and loamy deserts. The area of every type of desert has been defined by the analysis of the topography, geology, soil and landscape maps in scale from 1:100 000 to 1:1 000000 and materials of space information. The results obtained have been brought to concord with the data of "Soil Cadasters of Turkmenian SSR" for the years 1960-1985. All of these types of deserts are distributed disproportionally in the territory of the plains of Turkmenistan. They are concentrated as compact areas, due to the relief and geological composition of the territory, and the intensity of water and wind erosion, etc. The sandy deserts occupy the majority of the area $242990 \mathrm{sq}$. km. The stony-rubble ones are concentrated mainly at the North and $\mathrm{N}-\mathrm{W}$ and often combine with other types of deserts. Their total area is $44270 \mathrm{sq}$. $\mathrm{km}$. The area of loamy deserts is $45530 \mathrm{sq}$. $\mathrm{km}$. The main areas of loamy deserts are connected with the valleys and deltas of constant and seasonal water streams, foothills and near-mountain plains. Many loamy islands ("takyrs") are diffused in the falls of aeolian relief of sandy deserts.

Among the above-mentioned types of natural authomorphic ecosystems, there are also ecosystems of salty marshes and river-valleys in Turkmenistan plains. These ecosystems obtain supplementary water nutrition by surface and underground flow and cannot be inspected as authomorphic ones.

\subsection{Moisture income}

The data of moisture dynamics in the authomorphic desert ecosystems are obtained from the literature and official materials such as: "Meteorological annuals of Turkmen. SSR for the years 1929-1990" and works of Orlovsky [1], Romanov [2], Kunin [3], Kirsta [4] and others and computed correspondingly to the areas of authomorphic ecosystems.

The annual average amount of atmospheric precipitation, at the territory of Turkmenistan plains increases from $70-80 \mathrm{~mm}(\mathrm{~N})$ to $150-180 \mathrm{~mm}(\mathrm{~S})$; from 70 to $125 \mathrm{~mm}$ income over $46 \%$ of the territory, from $125 \mathrm{~mm}$. to $150 \mathrm{~mm}$. income over $17 \%$ of the area and from 150 to $200 \mathrm{~mm}$ over $37 \%$ of all the area of desert plains. Therefore, the average sum of annual precipitation here has been accepted for the following calculations as $110.4 \mathrm{~mm}$. Due to this data, $332790 \mathrm{sq}$. km of authomorphic desert ecosystems obtain, as average, $36,74 \mathrm{cu} . \mathrm{km}$ of atmosphere precipitation, which is near 36740 billion metric tons of moisture.

The most of this moisture (more than $80 \%$ ) falls during the cold season, when evaporation is weakened and, as a result, annual evaporation from the soil surface is relatively small - near $35 \%$ of annual income (data of Meteorology Service). It means that nearly 23881 bill. m. t. of rain water has time to penetrate into the soil before the beginning of summer drought. Nearly $11 \%$ of this moisture (4041,4 bill. m. t.) supplements the deep underground flow. The remaining quantity of moisture (19 840 bill. $\mathrm{m}$. t.) is distributed inside the soil profile and is drawn into life process of ecosystems, forming their organic components. 
The calculation, made on the basis of Beideman [5] for different dry land ecosystems, allowed us to define that most of this moisture is spent by plants during their life activity, mainly for transpiration (nearly 11000 bill. m. t.), and the remaining 8000-9000 bill. m. t. of water plays the main role in the forming of organic part of ecosystems.

\subsection{Formation of quantity of phytomass}

Regular geobotany investigations have been performed in the deserts of Turkmenistan since the end of the 1920's. The results defining the quantity of phytomass, its distribution over the area, and its seasonal and annual fluctuations have been presented in hydrometeorology reference books, soil cadastres and in numerous scientific investigations ([6-10] and others).

These data have been supplemented by materials of our field investigations, generalized and computed by conformity of the results of measurements of the areas of desert ecosystems of Turkmenistan, obtained from map and remote sensing materials.

According to the above-mentioned data, the average quantity of phytomass in authomorphic ecosystems of Turkmenistan plain deserts is defined as 242,42 bill. m. t. Over the period of a year, the quantity of phytomass changes from 218,31 bill. tons in the rainy spring to 76,87 bill tons- in dry summer, which correlates with the annual fluctuations of precipitation (from $46 \mathrm{~mm}$-spring to 5 $\mathrm{mm}$-summer). The common picture is complicated due to "physiological drought" in winter, as a result of low temperatures (from $-5{ }^{\circ} \mathrm{C}$ in the northern regions to $5-10{ }^{\circ} \mathrm{C}$ at the southern ones, with the minimum below $-25^{\circ} \mathrm{C}$ ).

The multi-annual fluctuations of precipitation and quantity of phytomass obviously correlate. The amount of precipitation in dry years $(67 \mathrm{~mm})$ is to 2,6 times less than in wet years $(173 \mathrm{~mm})$. It is reflected in the fluctuations of phythomass quantity by 2,8 times - from 119,14 bill. m. t. during dry year to 365,7 bill. m. t. during wet ones.

These calculations allow us to conclude that the average quantity of productive moisture income of $8000-9000$ bill. m. t. provides the formation and conservation of 242, 42 bill. m. t. of life phytomass, i.e. that 1 ton of organic material demands for its existence, as average, nearly 35 tons of water.

A significant quantity of moisture is used by plants for the creation of annual growth. It composes 55,88 bill. m. t. during the year of average income of precipitation $(110,4 \mathrm{~mm})$, which is $23 \%$ of the regular quantity of life biomass. The quantity of dead phythomass in authomorphic ecosystems is 82,96 bill. m. t. (34,22\% of the phytomass). The dead phytomass is created by the dying off of ephemerous plants and on-ground parts of ephemeroids at the beginning of the summer drought and the fall of dry leaves and shoots and dying parts of roots of trees and shrubs during the dry summer, cold autumn and winter. Part of this dead phytomass is removed during the year, part is carried off by wind and rainwater out of ecosystem, but part is conserved in the ecosystem for many years, which is the reason of why the quantity of dead phytomass is higher than the annual growth. 


\subsection{Formation of quantity of zoomass}

Both the live and dead phytomass are involved into the circulation of organic material in ecosystem as compost. It is the source of the formation and existence of animal life, from the simplest single-cell organisms to higher mammals. The quantity of phythomass, its consumption by animals and also the quantity of zoomass in the authomorphic desert ecosystems at the plains of Turkmenistan has been calculated on the basis of data of $[6,11-14]$ and others.

The calculations have demonstrated that consumption of phytomass by animals in authomorphic ecosystems in Turkmenistan plain deserts is almost 33 bill. m.t. tons during a year of average moisture. It is $10,14 \%$ of all the quantity of live and dead phytomass $(325,38$ bill. tons) or $59 \%$ of annual growth. This quantity provides the existence of 4,82 bill. $\mathrm{m}$. $\mathrm{t}$. of animal biomass, i.e. for the formation and activity of the $1 \mathrm{~m}$. t. of zoomass, $6,9 \mathrm{~m}$. t. of phytomass is demanded. The annual quantity of zoomass is exposed to seasonal and multiyear fluctuations reflecting the fluctuations of quantity of phytomass and precipitation. In dry years it is 2,39 bill. $\mathrm{m}$. $\mathrm{t}$. and in wet years - 7,26 bill. $\mathrm{m}$. $\mathrm{t}$. The quantity of zoomass in wet years is three times the quantity of dry years, similar to the quantity of precipitation and phytomass in wet and dry years. It is complementary evidence of direct correlation of these three values.

The next process of circulation of materials in an ecosystem is formation of animal wastes. The average annual quantity of wastes is approximately 22,97 bill. m. t, including 6 bill. m. t. of solids, 1,47 bill. m. t. of liquids and 15,5 bill. m. t. of gaseous wastes. About 5 bill. m. t. of used organic material is concentrated in organisms of animals, which live more than 1 year and return to circulation with the dead zoomass. All wastes and remnants of dead organisms enter the air, soil and underground water and are used by plants for the formation of new phytomass. The cycle is complete.

\subsection{Deductions}

The main active components of the authomorphic ecosystems of the plain deserts of Turkmenistan are connected in the following proportion: 8500 bill. m. $t$. of water $-242,4$ bill. m.t. of phytomass - 4,8 bill. m. t. of zoomass, or, accepting the zoomass as a unit - 1171:50:1. This correlation, formed during the process of evolution, may be accepted as optimal for the conservation and stability of desert ecosystems. Fluctuations in the amount of precipitation by as much as 2,6-2,8 times lead to fluctuations in the quantity of phytomass in the same boundaries and to fluctuations in the quantity of zoomass of approximately 3 times. These fluctuations don't result in irreversible damage of environment and degradation of ecosystems.

The attribute of elasticity of ecosystems, their capability to maintain stability, is manifested also in the conditions of multi-century fluctuations of climate, noted in the works of Kostiukovsky [15], Lisitzina [16], Vinogradov and Mamedov [17] and others. These data testify that the ecosystems of the plain deserts of Turkmenistan have maintained their countenance and fullness during no less than the last 15,000 years (since the Holocene age), notwithstanding periodical alternations of the warm and cold, wet and dry periods [18-21]. 


\section{Conclusion}

During the last 8000-9000 years, throughout the territory of Turkmenistan, special types of ecosystems - man-made ecosystems - were created. These ecosystems include the special character of hydrographical nets (canals, waterbodies, irrigate systems), relief (plane agricultural fields, buildings, dams, roads, etc.), special microclimate, cultural vegetation, and animal life.

The area of man-made ecosystems throughout the plains of Turkmenistan has increased from $20 \mathrm{~km}$ - 9000 years ago (data of Kostiukovsky [15], Masson [22], Lollekova [23], Lisitzina [24]) up to $80000 \mathrm{~km}$ (statistic data for 1995). $\mathrm{Up}$ to the end of the $19^{\text {th }}$ century, the growth of man-made ecosystems cramped to a significant degree the natural hydromorphic ecosystems of river valleys, deltas and foothill plains, but almost hadn't influenced the authomorphic desert ecosystems. The nomadic cattle-breeding tribes, widespread in their territory, tended to cramp the area occupied by wild large mammals (onagres, gazelles, saiga) excluding them from most pastures and water sources, but the role of these animals in the desert ecosystems passed to the herds of domestic cattle.

During the 20th century the human pressure on the natural ecosystems became threatening in character. The consumption of water for irrigation and other agricultural and industrial aims has led, on the one hand, to the drying up of the Aral sea and hydromorphic ecosystems in the valleys and deltas of rivers and, on the other hand, to formation of salty marshes and polluted water-bodies of the waste water in place of authomorphic desert ecosystems. The creation of highways, pipelines, power-lines, passage of off-road vehicles have all resulted in the destruction of soil surface, intensification of wind and water erosion, reduction of plants and animals, pollution of air and soil. The same problems, in non-comparative large grade are typical for all types of settlements, their neighborhood and the environs of industrial and mine regions. The grazing of cattle increased in intensity, exceeding the limits of sustainability of ecosystems of desert pastures and, in some of cases, has led to the full degradation of the environment, leading to catastrophic desertification. Nearly $80 \%$ of the territory of Turkmenistan is now exposed to desertification.

In such a manner, the problem of conservation of natural ecosystems and their sustainability, the regulation of human pressure, rational using of the nature is the problem of existence for human population. The monitoring of naturehuman interaction, planning of the human activity at the natural environment, nature conservation, creation of the reserves is the daily necessity. During the decision of all of these problems the discount of the keeping of proportional correlation of water regime and activity of biota as the base of sustainability of ecosystems is necessary.

\section{References}

[1] Orlovsky, N. S., Climate of Turkmenistan. Biogeography and Ecology of Turkmenistan. V. Fet and K.I. Atamuradov (eds.). Kluwer Academic Publishers: Dorderecht/ Boston/ London, pp.23-48, 1994 
[2] Romanov N.N., About Short- Time Prediction of Early Frosts in Central Asia. Meteorology and Hydrology, pp.27-30, 1952.

[3] Kunin V.N., Water in the Deserts and Environment. Nauka: Moscow, 286 p., 1980.

[4] Kirsta B.T., The Disposition of Hydrology at the Western Regions of Central Asia. Y1Ym: Ashgabat, 295 p., 1976.

[5] Beideman I.N., Reference Book of the Expenditure of Water by Plants in the Natural Zones of USSR (geobothany and ecology characteristic). Nauka: Novosibirsk, 256 p., 1983

[6] Productivity of the Vegetation of the Arid Zone of Asia (The Results of Soviet Investigations under International Biology Program, 1965-1974). Nauka: Leningrad, 232 p., 1977.

[7] Nikolaev V.N. The Natural Fodder Sources of Turkmenistan. Ylym: Ashgabat, 190 p., 1972.

[8] Netchaeva N. T., Antonova K.G. Biological Productivity of On-Ground mass of the Main Formations. Vegetation of Central Karakum and its Productivity. Ylym: Ashgabat, pp. 101- 109, 1970.

[9] Netchaeva N.T. Dynamics of pasture vegetation of Kara-Kum under the Influence of Meteorology Conditions. A.N.TSSR Publishers: Ashgabat, 214 p., 1958.

[10] Arnageldyev A., Kostiukovsky V.I. Ecosystems of Karakum. Ylym: Ashgabat, 311 p. 1988.

[11] Wildlife of USSR. Desert Zone. A.N. USSR: Moscow- Leningrad, vol. 2, 366 p., 1948.

[12] Nature Conservation in Turkmenistan. (4), Turkmenistan: Ashgabat, 178 p., 1978.

[13] Abaturov B. D. Mammals, as a Share of Ecosystems (Example of Herbivourous Mammals of the Hemi-Deserts). Nauka: Moscow, 286 p., 1984.

[14] Formozov A.N. The Main Peculiarities of Wildlife of the Plain Part of Central Asia. Central Asia. A.N. USSR Publishers: Moscow, pp.392-419, 1958.

[15] Kostiukovsky V. The History of Human Activity and Desertification in the Territory of Turkmenistan. Journal of Arid Land Studies Vol. 14,S, pp. 203- 206, 2004.

[16] Lisitzina G.N. The vegetation of Southern Turkmenistan at the VI- I Thousand Years B.C., by the Data of Coals. Karakum Antiquities, 3, Ylym: Ashgabat, pp.51- 56, 1968.

[17] Vinogradov A.V., Mamedov E. Landscape and Climatic Conditions in the Deserts of Central Asia in Holocene Period. The History of the Material Culture of Uzbekistan. II Fan: Tashkent, pp.32-44, 1974

[18] Mamedov E. Fluctuations of the Climate of Central- Asian Deserts in Holocene. The Fluctuations of Moisture of Aral- Caspian Region in Holocene. Nauka: Moscow, pp.170- 174, 1980.

[19] Budyko M.I. Climate in the Past and Future. Hydrometeoizdat: Leningrad, 351 p. 1980. 
[20] Kind N.V. Paleo-Climate and Nature Environment at the Holocene. The History of Bio-Geocenoses of USSR in Holocene. Nauka: Moscow, pp. 5$14,1976$.

[21] Gribbin J., Lem G. The Fluctuations of Climate during the Historical Period. Climatic Fluctuations. Hydrometeoizdat: Leningrad, 102- 121, 1980.

[22] Masson V.M. First Civilizations. Nauka: Leningrad, 275 p., 1989.

[23] Lollekova O. The Local Variability in the Culture and House-Keeping of Jeitun Tribes. Ylym: Ashgabat, 178 p., 1988.

[24] Lisitzina G.N. Origin and Development of Irrigated Agriculture at the South of Turkmenistan. Nauka: Moscow, 239 p., 1978. 